\section{International Scientific Journal Theoretical \& Applied Science}

p-ISSN: 2308-4944 (print) e-ISSN: 2409-0085 (online)

Year: 2015 Issue: 04 Volume: 24

Published: $30.04 .2015 \quad$ http://T-Science.org

SECTION 6. Metallurgy and energy.
Yuriy Ivanovich Savchenko

Candidate of Physical and Mathematical Sciences, associate professor, head of the physics department, Nosov Magnitogorsk State Technical University, Russia jura_sav@mail.ru

Olga Nikolaevna Vostroknutova Assistant professor of the physics department, Nosov Magnitogorsk State Technical University, Russia olvos@mail.ru

Gleb Yuryevich Savchenko Graduate student,

Nosov Magnitogorsk State Technical University, Russia gleb_savchenko@mail.ru

\title{
SYSTEM OF NONDESTRUCTIVE CONTROL FOR THE BLAST FURNACE LINING
}

\begin{abstract}
This article deals with an important role of the lining in realization of smooth running of the blast furnace. Provides an overview of existing methods of diagnosis of the condition of the lining. Describes the methodology of nondestructive testing, based on the detection of acoustic waves on the shell of the blast furnace to produce their spectrum. Proposed the multi-parameter control method.

Key words: blast furnace, lining, nondestructive testing, acoustic method of diagnostics, multiply construction. Language: Russian

Citation: Savchenko YI, Vostroknutova ON, Savchenko GY (2015) SYSTEM OF NONDESTRUCTIVE CONTROL FOR THE BLAST FURNACE LINING. ISJ Theoretical \& Applied Science 04 (24): 22-26.

Soi: http://s-o-i.org/1.1/TAS*04(24)4 Doi: crossef http://dx.doi.org/10.15863/TAS.2015.04.24.4

\section{СИСТЕМА НЕРАЗРУШАЮЩЕГО КОНТРОЛЯ СОСТОЯНИЯ ФУТЕРОВКИ ДОМЕННОЙ ПЕЧИ}

Аннотация: В данной статье рассмотрена важная роль футеровки в реализаџии ровного хода доменной печи. Дан обзор существующих методов диагностики состояния футеровки. Описана методика неразрушающего контроля, основанная на регистращии акустических колебаний на кожухе доменной печи с иелью получения их спектра. Предложен многопараметровый метод контроля.

Ключевые слова: доменная печь, футеровка, неразрушающий контроль, акустический метод диагностики, многослойная конструкция.
\end{abstract}

Доменная печь - это постоянно действующий агрегат шахтного типа, работа которого основана на противотоке поднимающихся вверх фурменных газов с непрерывно опускающейся и наращиваемой сверху шихтой.

Нормальной работой доменной печи называется ровный ход, который характеризуется рядом показателей. Прежде всего, это постоянная скорость схода шихты и наличие устойчивого гарнисажа. Распределение газового потока по сечению печи, которое характеризуется кривой содержания $\mathrm{CO}_{2}$ по диаметру ниже колошниковой защиты, должно быть стабильным, а нагрев по фурмам равномерным и устойчивым. Должны выполняться условия постоянства дутьевого режима по количеству, температуре, давлению, влажности и расходу природного газа и кислорода, а также постоянство общего и зональных перепадов давления газа по высоте печи, интенсивности горения кокса и выноса колошниковой пыли.
Кроме того, необходимо поддерживать стабильность температуры газа по абсолютному значению и умеренный диапазон ее колебания на периферии и колошнике. Тепловое состояние печи должно быть устойчивым и обеспечивать получение чугуна и шлака заданного состава, а также однородный состав чугуна по лёткам $[1 ; 2$, c. 17].

Основными отклонениями от нормального технологического состояния печи являются изменение нагрева, нарушение распределения периферийного и центрального газового потока, тугой ход доменной печи, устойчивое неравномерное распределение газа по окружности печи, канальный и односторонний ход печи. Кроме того, возможно загромождение горна, нарушение шлакового режима, потеря объема печи и подвисание шихты. Эти нарушения в различной степени уменьшают производительность доменной печи, повышают себестоимость чугуна, а также способствуют 
образованию дефектов футеровки [3, с 30; 4, с. 29].

Футеровка доменной печи предназначена для уменьшения тепловых потерь и предохранения кожуха от воздействия высоких температур. Она также защищает его от контакта с жидким металлом и шлаком [5].

Множество выявленных к настоящему времени факторов, способствующих разрушению огнеупорных материалов, из которых возводится футеровка, можно условно разделить на три группы [6, с. 53]:

- тепловые факторы, обусловленные высокими температурами и их колебаниями во времени, а также большими градиентами температур по высоте и сечению кладки;

- физико-химические факторы, связанные с размывающим действием чугуна и шлака, отложением углерода и цинка, взаимодействием рабочего слоя футеровки с компонентами, понижающими его огнеупорность;

$$
\text { механические факторь }
$$

(удары загружаемой шихты, истирание опускающимися материалами и восходящим газовым потоком, несущим абразивную пыль, давление газа, шихты и расплавов, расклинивающее действие застывшего чугуна, всплывание огнеупорных изделий под действием выталкивающей силы при проникновении чугуна и свинца в швы кладки).

Наиболее интенсивно огнеупорная футеровка изнашивается в первые четыре месяца ее эксплуатации. Различают футеровку по зонам. Различные факторы доменного производства негативно влияют на футеровку разных зон. Тепловое и химическое воздействие возрастает от верха печи к низу. При повышении температуры усиливается насыщение огнеупорных материалов примесями, понижающими его огнеупорность вплоть до расплавления, т.е. происходит шлакование огнеупоров.

Механические нагрузки преобладают главным образом в верхних двух третях высоты шахты и имеют свой максимум в цилиндрической части колошника. Кладка печи здесь испытывает максимальное ударное воздействие от падающих с засыпного аппарата шихтовых материалов. Выделяют такие дефекты футеровки, как разгары, настыли и выбоины.

Футеровка нижней части шахты и футеровка заплечиков в наибольшей степени подвержены износу и фактически определяют срок службы доменной печи. Основными причинами износа огнеупоров в этих местах является химическое воздействие шлаков (особенно в нижней части шахты), паров щелочей, монооксида углерода, цинка, значительные колебания температур, способствующие возникновению термических ударов, а также абразивный износ, создаваемый опускающейся шихтой и жидким чугуном.
Состояние футеровки доменной печи определяет рабочий профиль. Профиль доменной печи, ограничивающий ее рабочее пространство, так называемый «полезный объем», является важнейшей частью конструкции печей. Создание рационального профиля позволяет достичь устойчивого режима работы (ровного хода) доменной печи [7, с 6; 8, с. 15].

Поскольку восстановить профиль печи технологическими методами практически невозможно, то возрастает роль контроля работы печи визуально или по данным контрольноизмерительных приборов.

Так как футеровка в доменной печи крайне важна, то её состояние необходимо контролировать. При этом имеется ряд особенностей, которые необходимо учитывать. Доменная печь является агрегатом закрытого типа с многослойной конструкцией, внутри которой поддерживаются высокие температуры и высокое давление. Существуют различные методы диагностики и контроля остаточной толщины футеровки [9, с. 18].

Теплотехнический метод. Для его реализации проводят контроль тепловых нагрузок на холодильник, закладку термопар в кладку доменной печи, контроль температуры кожуха. Однако срок службы термопар много меньше времени кампании печи, что требует остановки производства и замены термопар.

Радиационный метод. Реализуется при помощи закладки радиоактивных изотопов в кладку доменной печи. По радиоактивному фону судят о разрушении. Однако такой метод не даёт возможности установить степень и место дефекта.

Аналитический метод. Сбор данных всех датчиков доменной печи с их последующей обработкой. Очень неточный и трудоёмкий способ контроля.

Взятие керна. Производят бурение кладки, в процессе которого замеряют температуру. По результатам анализа керна и температурам судят об износе футеровки. Метод точечный и не даёт полной картины по всему объёму печи.

Акустический метод. Для реализации используют акустические волны для определения аномалий в кладке, полученные данные интерпретируются в схему расположения дефектов.

Был разработан акустический метод [10, с. 75] диагностики состояния футеровки доменной печи на основе регистрации резонансного спектра колебаний, установившихся в слоях футеровки. Для обработки результатов измерений строится математическая модель объекта.

В акустике известна задача о прохождении акустических волн через совокупность слоев [11]. Поэтому представляя футеровку доменной печи 
как многослойную конструкцию, которая может состоять из слоёв с разными акустическими свойствами (кожух, огнеупорный блок, кольцевая трещина, холодильник, набивка, рабочий объём) и зная, что работающая доменная печь является источником большого количества акустических волн с разными частотами, можно рассмотреть вопрос прохождения акустических волн через данную конструкцию, которая по своим свойствам близка к футеровке доменной печи. Коэффициент прохождения является частотно зависимым, так как на толщинах слоёв возникают резонансные явления и устанавливается стоячая волна.

Самая низкая частота установившейся стоячей волны соответствует первой гармонике. Условия установления стоячей волны зависят от акустических свойств на границе, поэтому одна и та же толщина может давать разные гармоники. Первая гармоника может возникать при совпадении толщины с половиной длины волны, когда по обе стороны слоя находятся более плотные или менее плотные материалы, или при совпадении толщины слоя с четвертью длины волны, если с одной стороны расположен более плотный слой, а с другой менее плотный.
Была написана программа, которая работала следующем образом: в каждом слое записывалось выражение для волны, бегущей как слева, так и справа (падающей и отражённой). Для каждой волны акустические свойства слоя определяли волновое число в данном уравнении. После чего с учётом граничных условий рассчитывался коэффициент пропускания. Для отладки данной методики программа позволяет, задав толщины слоёв, плотности материалов, скорости звука и коэффициенты затухания звука, рассчитать коэффициент пропускания [12].

На рис.1 представлен график зависимости коэффициента пропускания от частоты звуковой волны для такой многослойной конструкции. Следует обратить внимание, что на данном графике можно наблюдать пик, соответствующий установлению резонансной частоты в кольцевой трещине. Также видна периодическая структура, соответствующая слою, находящемуся рядом с кожухом, и менее ярко выраженная периодическая структура, соответствующая слою, находящемуся за кольцевой трещиной. При изменении толщин этих слоев расстояние между максимумами изменяется.

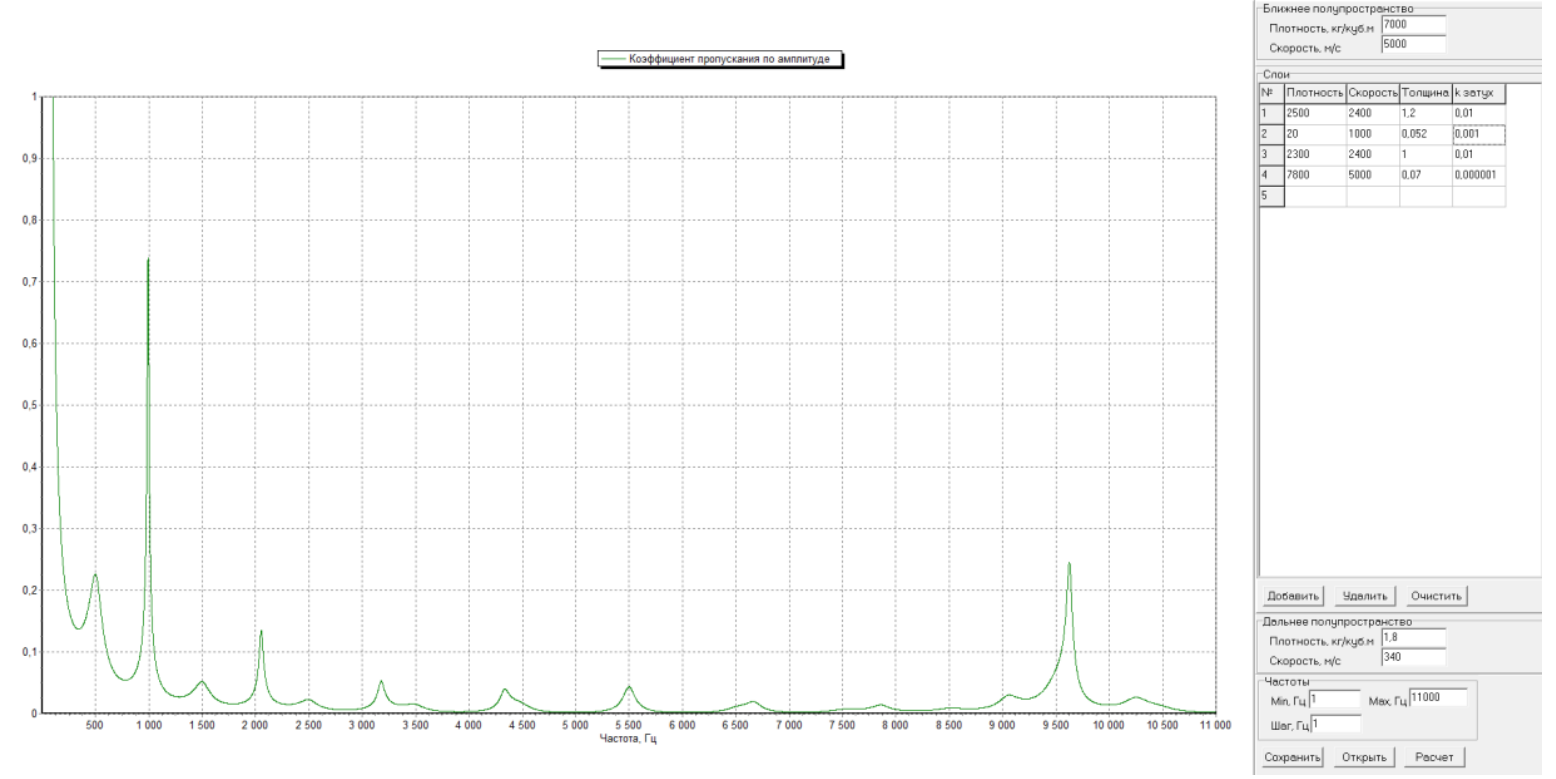

Рисунок 1 - Коэффициент пропускания многослойной конструкции.

Таким образом, замерив колебания на кожухе работающей доменной печи на заданном уровне, при помощи Фурье-преобразования можно определить толщины слоёв предполагаемой топографии футеровки. Предполагаемой, так как спектр колебаний достаточно богатый, и необходимо исключить всевозможные шумы и помехи, возникающие в таком сложном агрегате, как доменная печь. Кроме того наличие резонансных частот не говорит о последовательности расположения данных слоёв, поэтому чтобы построить топографию футеровки, необходимы дополнительные сведения. Их можно почерпнуть из истории работы доменной печи, либо из истории топографии футеровки, если такие замеры проводились ранее. В настоящее время ведется разработка и одновременно апробирование способа контроля состояния футеровки доменной печи с помощью стационарной многопараметровой диагностики. 
Impact Factor ISRA (India) $\quad=\mathbf{1 . 3 4 4}$

Impact Factor ISI (Dubai, UAE) $=\mathbf{0 . 8 2 9}$

based on International Citation Report (ICR)

Impact Factor GIF (Australia) $\quad \mathbf{0} \mathbf{0 . 3 5 6}$
Impact Factor JIF $\quad=\mathbf{1 . 5 0 0}$

Impact Factor SIS (USA) $\quad=0.912$

Impact Factor РИНЦ (Russia) $=\mathbf{0 . 1 7 9}$

Impact Factor ESJI (KZ) $\quad=\mathbf{1 . 0 4 2}$
Порядок многопараметрового метода контроля таков. Сначала в запоминающем устройстве регистрируется резонансный спектр колебаний, установившихся в футеровке. Затем в соответствии с математической моделью и с учётом свойств материалов определяются границы футеровки напротив мест установки датчиков. Далее осуществляется контроль других физических параметров многопараметровыми датчиками (температура, давление). Для каждого параметра строится собственная математическая модель. На основе каждой модели осуществляется построение топографии футеровки. И в конце производится проверка моделей на корреляционную связь, после чего строится окончательная топография футеровки $[13$, с. 30]. На рис.2 показано сравнение коэффициента пропускания, рассчитанного в выбранной модели и спектра реальных колебаний, установившихся на кожухе доменной печи.

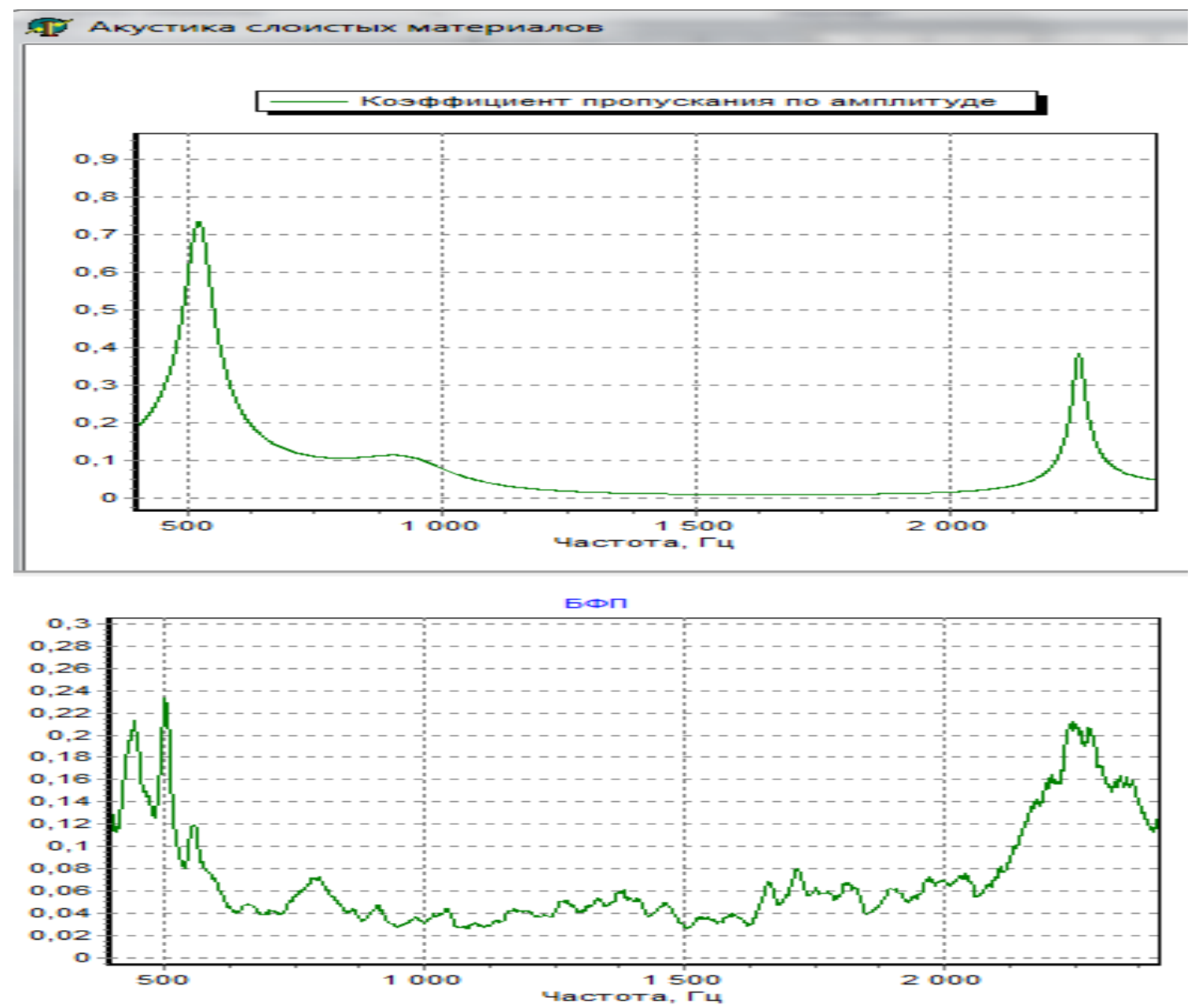

Рисунок 2 - Сравнение коэффициента пропускания выбранной модели и спектра установившихся колебаний на кожухе доменной печи.

Данный метод контроля позволяет обнаруживать образование настылей (плотная тугоплавкая масса застывшего металла или металлошлака) в доменной печи на ранних стадиях. При этом имеется возможность устранить настыль, например, при помощи истирания неофлюсованными окатышами, предотвратив тем самым нарушения хода работы доменной печи.

Также метод позволяет определить разгар (увеличение рабочего объема) горна, который может быть вызван разрушением гарнисажа стен и лещади при длительной работе на шлаках неустойчивого состава или пониженной основности и недостаточно высоким качеством лёточной массы. При этом возможно произвести заблаговременную фиксацию начала возникновения разгара, установить усиленный контроль за этим районом горна и принять меры для недопущения усиления разгара.

Таким образом, можно сказать, что при своевременном обнаружении на ранних стадиях

ISPC The Combination of Technology \&

Education, Östersund, Sweden 
начала возникновения дефектов футеровки можно значительно снизить негативные последствия, которые они оказывают на режим работы доменной печи.

Кроме того внедрение данной системы позволит производить плановый ремонт по фактическому состоянию футеровки, минимизирует вероятность аварии на производстве, что в свою очередь несёт дополнительный экономический эффект, а также способно сохранить человеческие жизни.

\section{References:}

1. Stefanovich MA, Sibagatullin SK, Gushchin DN (2011) Zakonomernosti dvizheniya shikhty i gaza v domennoy pechi, Magnitogorsk, MSTU after G.I. Nosov, 2011. 161 p.

2. Sibagatullin SK, Mayorova TV (2010) K raschetu pokazateley hoda domennogo protsessa pri povyshennom obshchem perepade davleniya gazov. Vestnik Magnitogorskogo gosudarstvennogo tehnicheskogo universiteta im. G.I. Nosova. 2010. № 3. pp. $16-18$.

3. Terentyev VL, Sibagatullin SK, Nefedov SN et al. (2003) Promyvka gorna domennoj pechi shlakom ot vyplavki ferromargantsa. Teoriya $\mathrm{i}$ tehnologiya metallurgicheskogo proizvodstva. 2003. № 3. pp. 29 - 33.

4. Sibagatullin SK, Harchenko AS, Chevychelov AV, Kolosov AV, Gostenin VA, Pishnograev SN (2010) Vliyanie koksovogo opeshka na fil'tratsiyu zhidkih produktov plavki $\mathrm{V}$ gorne domennoj pechi. Vestnik Magnitogorskogo gosudarstvennogo tehnicheskogo universiteta im. G.I. Nosova. 2010. № 4. pp. 28 - 30.

5. (2015) Prednaznachenie ogneupornoj futerovki $\mathrm{v}$ domennoj pechi. Available: http://uas.su/books/refrectory/81/razdel81.php (Accessed: 06.04.2015).

6. Rogov MV, Sibagatullin SK, Gulyaev GM et al. (1990) Issledovanie prichin iznosa kladki i sistemy ohlazhdeniya domennoj pechi № 4 ob'emom $2000 \mathrm{~m}^{3}$ OHMK. Bylleten' NTI. Chernaya metallurgiya. 1990. № 2. pp. 53-54.

7. Nefedov SN, Terentyev VL, Sibagatullin SK et al. (2002) Formirovanie karbidnogo garnisazha na futerovke gorna domennoj pechi. Chernye metally. 2002. № 1. pp. $5-7$.
8. Terentyev AV, Sibagatullin SK, Mavrov AL (2004) Formirovanie titanistogo garnisazha $\mathrm{V}$ domennoj pechi. Izvestiya vuzov. Chernaya metallurgiya. 2004. № 7. pp. $15-16$.

9. Savchenko GY, Bayukova VA, Vostroknutova ON, Lednov AY, Savinova NA (2013) Akusticheskaya model' futerovki domennoj pechi. Teoriya i tehnologiya metallurgicheskogo proizvodstva. 2013. № 1 . pp. $18-20$.

10. Savchenko GY, Bilichenko VI, Vostroknutova ON, Savochkina AS (2014) Review of nondestructive control methods of the blast furnace lining wear. Theoretical \& Applied Science. 2014. № 4 (12). pp. 73-75.

11. Brehovskih LM, Godin OA (1989) Akustika sloistyh sred. M.: Nauka. Gl. red. fiz-mat. lit., 1989. 416 p.

12. Savchenko YI, Savchenko GY, Lednov AY, Vostroknutova ON, Savinova NA (2015) Akusticheskaya model' futerovki domennoj pechi dlya realizatsii metoda sobstvennyh kolebanij. Available: http://www.rusnauka.com/28_NPM_2013/Tecn ic/1_145463.doc.htm (Accessed: 06.04.2015).

13. Arzamastzev AM, Lednov AY, Popov AV, Savchenko GY, Savchenko YI (2014) Diagnostika sostoyaniya futerovki domennoj pechi. Sovremennye metody i pribory kontrolya kachestva i diagnostiki sostoyaniya ob'ektov. Materialy 5-oj mezhdunarodnoj nauchnotehnicheskoj konferentsii. Mogilev. GU VPO "Belorussko-rossijskij universitet. 2014. pp. 29 -31 . 